\title{
Identifying frailty risk profiles of home-dwelling older people: focus on sociodemographic and socioeconomic characteristics
}

\author{
Sarah Dury ${ }^{\mathrm{a}}$, Ellen De Roeck $\mathbb{B}^{\mathrm{b}, \mathrm{c}}$, Daan Duppen ${ }^{\mathrm{a}}$, Bram Fret ${ }^{\mathrm{a}}$, Lieve Hoeyberghs ${ }^{\mathrm{d}}$, Deborah Lambotte ${ }^{\mathrm{a}}$, \\ Michaël Van der Elst ${ }^{e}$, Anne van der Vorst ${ }^{f}$, Jos Schols ${ }^{f, g}$, Gertrudis Kempen ${ }^{f}$, G.A. Rixt Zijlstra ${ }^{f}$, Jan De Lepeleire ${ }^{h}$, \\ Birgitte Schoenmakers ${ }^{\mathrm{h}}$, Tinie Kardol ${ }^{\mathrm{a}}$, Nico De Witte ${ }^{\mathrm{a}, \mathrm{d}}$, Dominique Verté ${ }^{\mathrm{a}}$, Liesbeth De Donder ${ }^{\mathrm{a}}$, \\ Peter Paul De Deyn ${ }^{b}$, Sebastiaan Engelborghs ${ }^{b}$, An-Sofie Smetcoren ${ }^{a}$ and Eva Dierckx ${ }^{c}$
}

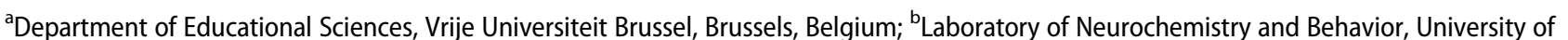
Antwerp, Antwerp, Belgium; 'Department of Clinical and Lifespan Psychology, Vrije Universiteit Brussel, Brussels, Belgium; ${ }^{\mathrm{d}}$ Faculty of Education, Health and Social Work, University College Ghent, Gent, Belgium; 'Department of General Practice, Catholic University of Leuven, Leuven, Belgium; 'Department of Health Services Research, CAPHRI School for Public Health and Primary Care, Maastricht University, Maastricht, The Netherlands; ${ }^{9}$ Department of General Practice, CAPHRI School for Public Health and Primary Care, Maastricht University, Maastricht, The Netherlands; ${ }^{\mathrm{h}}$ Department of Public Health and Primary Care, University of Leuven, Leuven, Belgium

\begin{abstract}
Objectives: This paper investigates risk profiles of frailty among older people, as these are essential for detecting those individuals at risk for adverse outcomes and to undertake specific preventive actions. Frailty is not only a physical problem, but also refers to emotional, social, and environmental hazards. Methods: Using data generated from the Belgian Ageing Studies, a cross-sectional study $(n=28,049)$, we tested a multivariate regression model that included sociodemographic and socioeconomic indicators as well as four dimensions of frailty, for men and women separately.

Results: The findings indicated that for both men and women, increased age, having no partner, having moved house in the previous 10 years, having a lower educational level and having a lower household income are risk characteristics for frailty. Moreover, when looking at the different frailty domains, different risk profiles arose, and gender-specific risk characteristics were detected.

Discussion: This paper elaborates on practical implications, and formulates a number of future research recommendations to tackle frailty in an aging society. The conclusion demonstrates the necessity for a thorough knowledge of risk profiles of frailty, as this will save both time and money and permit preventive actions to be more individually tailored.
\end{abstract}

\section{ARTICLE HISTORY}

Received 8 December 2015 Accepted 17 May 2016

\section{KEYWORDS}

Frail older adults; frailty; multiple linear regressions; populations at risk; risk factors

\section{Introduction}

The world's population has been aging intensely over the last few decades (United Nations, 2013). The rising proportion of older persons in the total population has profound consequences on a wide range of social, economic, and political processes (Börsch-Supan et al., 2013; Kowal et. al., 2012). Therefore, in most developed countries, care for older people is an increasing priority for governments, with approaches such as 'active aging' and 'aging in place' gaining more and more support (Walker \& Maltby, 2012). In line with these approaches, governments are making efforts to implement projects that help and motivate older people to remain living at home in order to prevent or delay the high costs of institutionalization (Scharlach, 2011). Aging in place is not only a governmental policy objective but also the preference of most older adults themselves (Löfqvist et al., 2013). As a consequence, bot frail and non-frail older people are increasingly living at home for as long as possible and desirable (Löfqvist et al., 2013).

Frailty is an emerging concept that is often used in research as a (clinical) phenotype (Fried et al., 2001) or an accumulation of health deficits (Etman, Burdorf, Van der Cammen, Mackenbach, \& Van Lenthe, 2012; Rockwood, Fox, Stolee, Robertson, \& Beattie, 1994). Yet older people themselves, as well as researchers, perceive frailty not only as a physical problem, but also as emotional, social, and environmental issues (De Witte, De Donder et al., 2013; De Witte, Gobbens et al., 2013; Grenier, 2007). More recently, multidimensional approaches have defined frailty as 'a dynamic state that affects an individual who experiences losses in one or more domains (physical, psychological, social, and more recently, also environmental) (De Witte, De Donder et al., 2013; De Witte, Gobbens et al., 2013), which is caused by the influence of a range of variables and which increases the risk of adverse outcomes' (De Lepeleire, lliffe, Mann, \& Degryse, 2009; Gobbens, van Assen, Luijkx, Wijnen-Sponselee \& Schols, 2010). Physical frailty refers to a wide range of physical problems such as reduced endurance, mobility or physical activity (Fried, Ferruci, Darer, Williamson, \& Anderson, 2004; Studenski, Hayes, \& Leibowitz, 2004). A recent consensus group consisting of delegates from six major international, European, and US societies defined physical frailty as 'a medical syndrome with multiple causes and contributors that is characterized by diminished strength, endurance, and reduced physiologic function that increases an individual's vulnerability for developing increased dependency and/or death' (Morley, Vellas, \& van Kan, 2013, p. 393). Psychological or emotional frailty includes depressive symptomatology and negative affects, anxiety, or sadness (Bravell, Westerlind, \& Midlöv, 2011). Social frailty encompasses a lack of social support, the absence of emotionally rewarding social contacts or 
loneliness (Steverink, Slaets, \& Schuurmans, 2001), while environmental frailty includes frailty in terms of poor-quality housing and deprived living environments (De Witte, De Donder et al., 2013; De Witte, Gobbens et al., 2013).

Frailty has a negative impact on the independency and selfreliance of older people, and, as a consequence, affects their ability to live self-reliantly at home (Buckinx et al., 2015). In order to be able to remain living at home for as long as possible, frailty needs to be detected in a timely manner, and the negative consequences have to be minimized. Therefore, an investigation of risk profiles leading to frailty in general and its different domains in particular (physical, psychological, social, and environmental) is essential for targeting those older individuals at risk for adverse outcomes and to undertake specific preventive actions (de Vries et al., 2011; Hoogendijk et al., 2014; Strandberg \& Pitkälä, 2007). A thorough knowledge of these risk profiles will also save time and money (Glynn et al., 2011; Mercer, Smith, Wyke, O'Dowd, \& Watt, 2009) and allows individually tailored interventions (Kelaiditi et al., 2013).

However, two important research gaps have been detected. First, most studies so far have focused on risk profiles for physical frailty (Etman, Kamphuis, van der Cammen, Burdorf, \& van Lenthe, 2015), and knowledge about the risk profiles of the other domains of frailty is very rare. A notable exception can be found in a Portuguese study, which revealed that age only plays a role with regard to physical frailty, and that women are more likely to be frail in all three investigated dimensions (i.e. physically, psychologically, and socially) (Coelho, Paùl, Gobbens, \& Fernandes, 2015a). In addition, a lower income level, the recent death of a loved one, or recent divorce (Drubbel et al., 2013), lower education, dissatisfaction with their living environment, and self-reported comorbidity might be related to the physical, psychological, and social domains of frailty (Coelho et al., 2015a). However, these latter studies did not examine environmental frailty. Second, the risk profiles of comprehensive, multidimensional frailty among home-dwelling older adults are currently almost nonexistent (Gobbens, Luijkx, Wijnen-Sponselee, \& Schols, 2010).

In order to prevent or delay frailty, a better understanding of the dynamic processes leading to frailty in older people is of primary interest. The first step in this process is identifying risk profiles in order to find these people who are in need of care and support (Ferrucci et al., 2004). Moreover, separate risk profiles for men and women have proven to be necessary because previous frailty studies have shown that the aging process differs by gender (de Vries et al., 2011; Mercer et al., 2009; Syddall et al., 2010). Likewise, more insight is necessary on the risk profiles for each specific domain of frailty in order to provide accurate case-finding, to target resources at individuals or groups that are more at risk than others, and make proactive care and support possible. Therefore, the main objective of this study is to explore the risk profiles in terms of sociodemographic characteristics and socioeconomic status of the different frailty domains (physical, psychological, social, and environmental) among older people living self-reliantly at home.

\section{Methods}

\section{Study design: Belgian Ageing Studies (BAS) survey}

For this study, the data from the Belgian Ageing Studies (BAS) was used. BAS is a cross-sectional, large-scale survey that used a structured questionnaire to collect information on various aspects related to the quality of life of communitydwelling older people aged 60 years and above from the Dutch-speaking part of Belgium. In the BAS survey, participants were selected through a participatory peer-research method. Older people were embraced as essential partners of the project. For instance, as partners in the data collection, older volunteers were recruited through local authorities and associations, and trained on how to deliver and collect the questionnaires personally. The questionnaires were selfadministered, but on request, the volunteers were allowed to clarify questions. The respondents were free to participate, and their anonymity was guaranteed. The respondents were assured of their right to refuse to answer and of their privacy. More information on the data collection method can be found in a methodological paper (De Donder et al., 2014). The ethical committee of the Vrije Universiteit Brussel approved the study protocol (B.U.N. 143201111521).

\section{Participants}

The current study was carried out in 83 municipalities between 2008 and 2014. The sampling fraction depended on the size of the municipality and varied between $N=109$ and $N=984$. In each municipality, addresses were randomly selected from the census records by the local authorities. The sample was stratified using quotas for gender and age $(60-69,70-79$, and $80+$ years) to ensure that the sample matched the makeup of the underlying population in the municipality. Inclusion criteria for the research were being older than 60 years and community dwelling (i.e. older people living in residential care facilities were excluded from the sample). The questionnaire was available in several languages (Dutch, French, English, German, Turkish, etc.) to ensure maximum participation of older migrants. If the respondents refused or were hampered to fill in the questionnaire (e.g. due to cognitive impairment or hospitalization), the volunteers received replacement addresses in the same quota category to allow the intended sample size to be obtained.

In the following analyses, we excluded cases with missing responses to the main measures (described in greater detail in the next section), resulting in a final sample of 28,049 respondents, with a median age of 70 years: $54.3 \%$ were women, $69.3 \%$ were married, approximately $52.3 \%$ of the households had a monthly income of less than $€ 1500$, and $66.2 \%$ had a low educational profile.

\section{Variables and measurement}

The dependent variable frailty was measured using the Comprehensive Frailty Assessment Instrument (CFAl) (Appendix 1) (De Witte, De Donder et al., 2013; De Witte, Gobbens et al., 2013), which is a self-administered instrument, and measures four domains of frailty (i.e. outcome variables). For the physical domain of frailty, the respondent's general physical health was assessed (four items, e.g. walking up a hill or stairs). The psychological domain was captured by measuring mood-disorders and emotional loneliness (eight items, e.g. losing self-confidence). The social domain of frailty was evaluated by older people's social loneliness (three items, e.g. enough people I feel close to) and their social support (three items, e.g. social support network). Finally, the environmental domain of frailty was assessed by propositions regarding the suitability of the physical housing environment; inadequacy 
in this area can threaten the mobility of aging individuals because of a lack of comfort (five items, e.g. insufficient comfort in the house). The scores for the subscales were calculated by adding the scores of the specific items: all subscales ranged from 0 to 100. The total score of the CFAl was calculated by summing the scores for each indicator. The CFAI was previously validated (De Witte, De Donder et al., 2013; De Witte, Gobbens et al., 2013), using a second-order confirmatory factor analysis. The model showed good model fit indices, including the Root Mean Square Error of Approximation (RMSEA $=0.032 ; 90 \%$ interval $=0.032-0.033$ ), Comparative Fit Index $(\mathrm{CFI}=0.974)$ and Tucker-Lewis Index $(\mathrm{TLI}=0.970)$. The CFAl also proved to be internally consistent, with a Cronbach's $\alpha$ of 0.812 , explaining $63.6 \%$ of the variance in frailty.

Two categories of independent variables were included in the model: sociodemographic characteristics: age (measured per 5 years), gender ( $1=$ male, $2=$ female) and marital status ( $1=$ married, $2=$ cohabiting, $3=$ widowed, $4=$ divorced, $5=$ never married). Whether the participants had moved house in the previous 10 years $(1=$ no, $2=$ yes) and their country of birth were also recorded $(1=$ born in Belgium, $2=$ born in Europe, 3 = born outside Europe). In terms of socioeconomic characteristics, the level of education used the highest level of education obtained (recoded into the categories: no degree or primary education; lower secondary; higher secondary; higher education), and the monthly household income $(1=<€ 999,2=$ between $€ 1000$ and $€ 1499,3=$ between $€ 1500$ and $€ 1999,4=>€ 2000$ ) was also evaluated.

\section{Statistical methods}

The study tested 10 models regarding the influence of sociodemographic and socioeconomic characteristics on four domains of frailty (physical, psychological, social, environmental) and total frailty, for men and women separately. Bivariate and multivariate linear regression models were applied for this study. First, to explore the differences in the CFAl scores between the groups, intergroup differences in the CFAl scores were examined using Mann-Whitney U-test or Kruskall-Wallis test (Appendix 2), due to non-normality of the data. Independent variables (sociodemographic and socioeconomic characteristics) that were not significantly related to frailty were not included in the next step of the analysis. In order to check for problems related to intercorrelations between the independent variables, collinearity diagnostics were checked. The cut-off criterion was set at a variance inflation factor (VIF) of $>10.0$, which indicates a multicollinearity problem (Field, 2013). Finally, a multiple linear regression analysis for men and women separately was used to measure the relative importance of each independent variable. Given the large sample size, statistical significance was set at $p$ $<.01$ and $p<.001$ for all the analyses. All analyses were performed in SPSS 22 (IBM Corp., Armonk, NY, USA)

\section{Results}

Table 1 presents the bivariate statistics for the relationships between the independent variables, sociodemographic and

Table 1. Characteristics baseline and comparison within groups $(n=28,049)$.

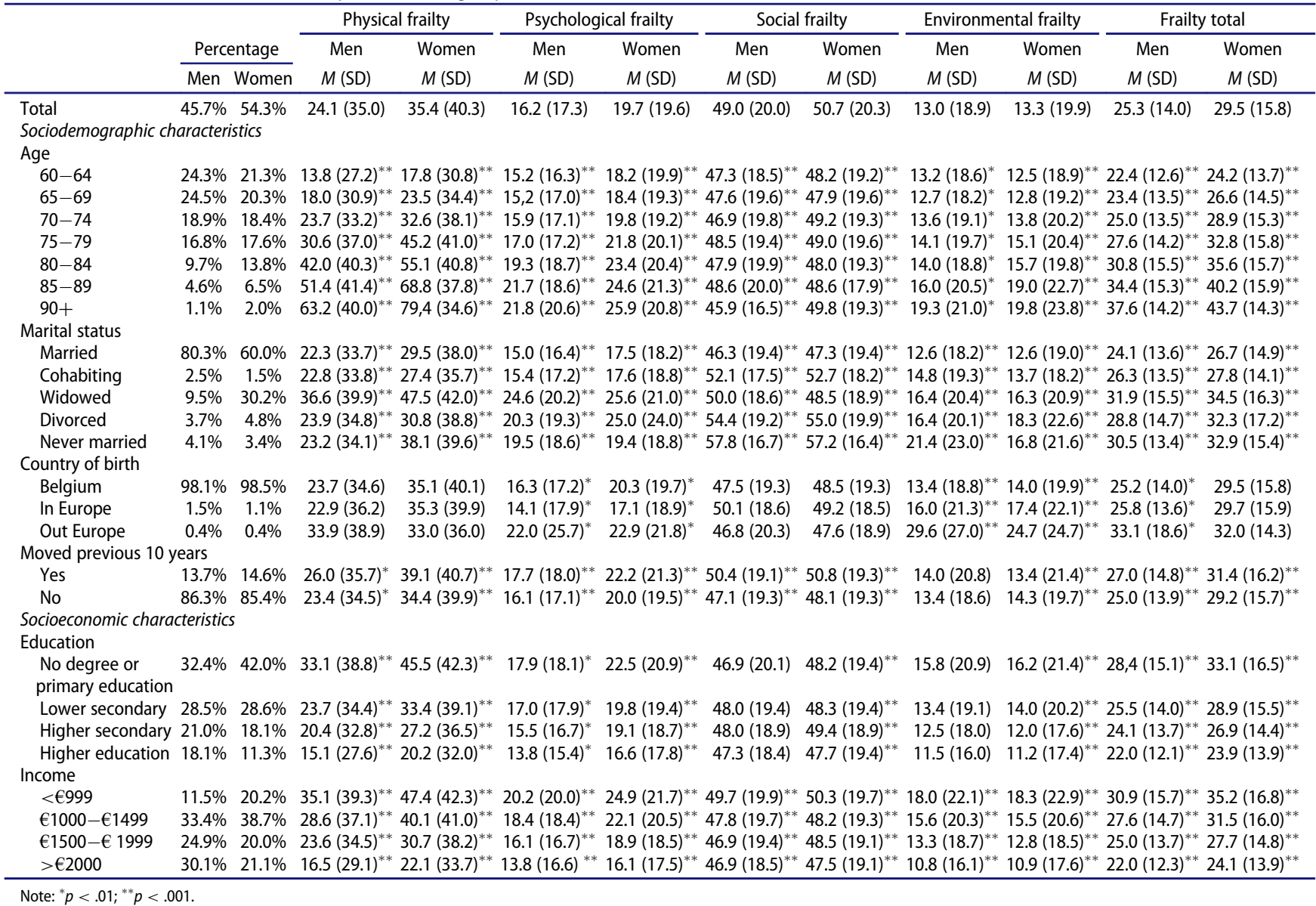

Note: ${ }^{*} p<.01 ;{ }^{* *} p<.001$ 
socioeconomic characteristics, and mean scores and standard deviation for each domain of frailty and multidimensional frailty included in our study. For the physical domain, only the country of birth showed no significant differences for men and women (Kruskall-Wallis: $\chi^{2}(2)$ men $=4.2, p=.124 ; \chi^{2}(2)$ women $=.09, p=.956$ ). Furthermore, the social frailty domain showed no significant differences between the groups for country of birth between men and women $\left(\chi^{2}(2)\right.$ $\left.=4.1, p=.127 ; \chi^{2}(2)=0.7, p=.716\right)$ and the level of education only for men $\left(\chi^{2}(2)=10.8, p=.013\right)$. For the environmental frailty domain, both moved previous 10 years (Mann-Whitney $U=1436292, p=.887$ ) and the level of education $\left(\chi^{2}(2)=2.3, p=.506\right)$ among men showed no significant differences between groups. Finally, the country of birth indicated no significant differences only for women in multidimensional frailty $\left(\chi^{2}(2)=2.2, p=.326\right)$.

In the second phase, 10 multiple linear regression analyses were carried out to identify the risk profiles based on sociodemographic and socioeconomic characteristics for the four frailty domains and multidimensional frailty, for both men and women separately (Table 2). Across both gender groups, two variables remained significant in all models: having moved in the last 10 years and the monthly household income. Older people who had moved in the last 10 years appeared to be frailer compared to people who had not moved in the previous 10 years. However, there was one exception: women who had moved in the last 10 years experienced less environmental hazards. The role of household income was clear: men and women with a higher monthly household income were less likely to be frail, in all domains.

Additionally, in each frailty domain, specific risk characteristics emerged. Older people with higher levels of physical frailty were more likely to be older, have moved in the last 10 years, have a lower level of education and have a lower monthly household income. Physical frailty starts to increase already from as early as the age of 65 years.

Older people who had not moved in the last 10 years, had a partner, had attained the highest educational level, and had higher levels of household income were less likely to be psychologically frail. However, widowed, divorced, or never-married men and widowed and divorced women were more likely to be psychologically frail.

Regarding social frailty, the following risk characteristics were found: higher age, not being married, having moved in the last 10 years, and lower monthly household income.

For environmental frailty, people born outside Belgium, without a partner, with a lower educational level, and with a lower monthly household income experienced greater frailty. Men who were divorced or never married experienced more environmental frailty, while being widowed or divorced among women was associated with more environmental frailty.

The analysis of multidimensional frailty (CFAl total) demonstrated that the older, the lower the educational level, and the lower the household income of older people, the more likely they were to be frail. Men were less likely to be frail when they were married. For women, being married or cohabiting protected them from being frail. Men who were born outside Europe were also more likely to be frail.

Finally, considering the analyses on gender-specific risk profiles, the findings only demonstrate no different risk characteristics between men and women within the domain of physical frailty. As for the other domains of frailty, gender-specific risk profiles emerged. Never-married men are at risk for psychological frailty; the age of onset for social frailty is earlier among women, and higher education is a protective factor for women (but not for men). Looking at environmental frailty, again never-married men are an additional risk group, as well as migrant older men being born in and outside

Table 2. Standardized results of the 10 linear regression models within the different frailty domains $(n=28,049)$.

\begin{tabular}{|c|c|c|c|c|c|c|c|c|c|c|}
\hline & \multicolumn{2}{|c|}{ Physical frailty } & \multicolumn{2}{|c|}{ Psychological frailty } & \multicolumn{2}{|c|}{ Social frailty } & \multicolumn{2}{|c|}{ Environmental frailty } & \multicolumn{2}{|c|}{ Frailty Total } \\
\hline & $\begin{array}{l}\text { Men } \\
\text { Std B }\end{array}$ & $\begin{array}{l}\text { Women } \\
\text { Std B }\end{array}$ & $\begin{array}{l}\text { Men } \\
\text { Std B }\end{array}$ & $\begin{array}{c}\text { Women } \\
\text { Std B }\end{array}$ & $\begin{array}{l}\text { Men } \\
\text { Std B }\end{array}$ & $\begin{array}{l}\text { Women } \\
\text { Std B }\end{array}$ & $\begin{array}{l}\text { Men } \\
\text { Std B }\end{array}$ & $\begin{array}{l}\text { Women } \\
\text { Std B }\end{array}$ & $\begin{array}{l}\text { Men } \\
\text { Std B }\end{array}$ & $\begin{array}{l}\text { Women } \\
\text { Std B }\end{array}$ \\
\hline \multicolumn{11}{|c|}{ Sociodemographic characteristics } \\
\hline $65-69$ & $0.039^{* *}$ & $0.043^{* *}$ & -0.004 & -0.005 & 0.016 & 0.013 & -0.020 & -0.002 & 0.020 & 0.023 \\
\hline $70-74$ & $0.085^{* *}$ & $0.119^{* *}$ & -0.006 & 0.000 & 0.003 & $0.042^{* *}$ & -0.011 & -0.008 & $0.053^{* *}$ & $0.082^{* *}$ \\
\hline $75-79$ & $0.141^{* *}$ & $0.208^{* *}$ & 0.007 & 0.001 & $0.041^{* *}$ & $0.042^{* *}$ & -0.011 & 0.004 & $0.098^{* *}$ & $0.146^{* *}$ \\
\hline $80-84$ & $0.202^{* *}$ & $0.262^{* *}$ & 0.022 & 0.007 & $0.03^{*}$ & 0.014 & -0.020 & 0.009 & $0.135^{* *}$ & $0.175^{* *}$ \\
\hline $85-89$ & $0.197^{* *}$ & $0.264^{* *}$ & $0.031^{*}$ & 0.007 & 0.008 & 0.005 & 0.006 & 0.029 & $0.134^{* *}$ & $0.185^{* *}$ \\
\hline 90 and above & $0.127^{* *}$ & $0.184^{* *}$ & 0.010 & 0.018 & -0.006 & -0.004 & 0.020 & 0.020 & $0.082^{* *}$ & $0.128^{* *}$ \\
\hline \multicolumn{11}{|c|}{ Marital status: Married (ref.) } \\
\hline Cohabiting & 0.001 & -0.003 & 0.008 & 0.003 & $0.044^{* *}$ & $0.034^{* *}$ & 0.017 & 0.003 & $0.028^{*}$ & 0.013 \\
\hline Widowed & 0.013 & 0.011 & $0.127^{* *}$ & $0.144^{* *}$ & $0.055^{* *}$ & $0.034^{*}$ & 0.023 & $0.036^{* *}$ & $0.076^{* *}$ & $0.065^{* *}$ \\
\hline Divorced & 0.015 & 0.010 & $0.047^{* *}$ & $0.068^{* *}$ & $0.074^{* *}$ & $0.08^{* *}$ & $0.026^{*}$ & $0.055^{* *}$ & $0.053^{* *}$ & $0.070^{* *}$ \\
\hline Never married & -0.009 & -0.002 & $0.038^{* *}$ & 0.012 & $0.108^{* *}$ & $0.089^{* *}$ & $0.062^{* *}$ & 0.018 & $0.065^{* *}$ & $0.031^{* *}$ \\
\hline \multicolumn{11}{|c|}{ Country of birth: Belgium (ref.) } \\
\hline In Europe & -0.004 & 0.001 & -0.017 & -0.016 & 0.009 & -0.004 & $0.023^{*}$ & 0.014 & 0.001 & -0.001 \\
\hline Out Europe & 0.013 & -0.001 & 0.018 & 0.003 & -0.011 & 0.003 & $0.057^{* *}$ & $0.027^{*}$ & $0.031^{* *}$ & 0.008 \\
\hline \multicolumn{11}{|c|}{ Moved previous 10 years: No (ref.) } \\
\hline Yes & $0.044^{* *}$ & $0.052^{* *}$ & $0.027^{*}$ & $0.028^{*}$ & $0.041^{* *}$ & $0.034^{* *}$ & 0.008 & $-0.027^{*}$ & $0.054^{* *}$ & $0.043^{* *}$ \\
\hline \multicolumn{11}{|c|}{ Socioeconomic characteristics } \\
\hline \multicolumn{11}{|c|}{ Level of education: No degree/primary (ref.) } \\
\hline Lower secondary & $-0.059^{* *}$ & $-0.059^{* *}$ & 0.002 & -0.025 & 0.006 & -0.008 & $-0.030^{* *}$ & -0.024 & $-0.040^{* *}$ & $-0.062^{* *}$ \\
\hline Higher secondary & $-0.072^{* *}$ & $-0.076^{* *}$ & -0.009 & -0.020 & 0.01 & 0.007 & $-0.023^{*}$ & $-0.044^{* *}$ & $-0.051^{* *}$ & $-0.072^{* *}$ \\
\hline Higher education & $-0.097^{* *}$ & $-0.095^{* *}$ & $-0.031^{*}$ & $-0.043^{* *}$ & -0.005 & $-0.041^{* *}$ & $-0.029^{*}$ & $-0.035^{* *}$ & $-0.084^{* *}$ & $-0.101^{* *}$ \\
\hline \multicolumn{11}{|c|}{ Monthly household income: $<€ 999$ (ref.) } \\
\hline$€ 1000-€ 1499$ & $-0.045^{*}$ & $-0.042^{* *}$ & -0.015 & -0.029 & -0.028 & $-0.038^{*}$ & -0.032 & -0.028 & $-0.052^{*}$ & $-0.62^{* *}$ \\
\hline$€ 1500-€ 1999$ & $-0.067^{* *}$ & $-0.058^{* *}$ & $-0.045^{*}$ & $-0.044^{* *}$ & $-0.043^{*}$ & -0.028 & $-0.053^{* *}$ & $-0.055^{* *}$ & $-0.089^{* *}$ & $-0.079^{* *}$ \\
\hline$>€ 2000$ & $-0.118^{* *}$ & $-0.085^{* *}$ & $-0.083^{* *}$ & $-0.075^{* *}$ & $-0.046^{*}$ & $-0.038^{*}$ & $-0.102^{* *}$ & $-0.072^{* *}$ & $-0.155^{* *}$ & $-0.123^{* *}$ \\
\hline
\end{tabular}

Note: Std B, Standardized beta regression coefficients; ${ }^{*} p<.01 ;{ }^{* *} p<.001$. 
Europe. Considering the total frailty, cohabiting men and older men born outside of Europe are at risk.

\section{Discussion}

The main goal of this study was to explore which sociodemographic and socioeconomic characteristics are related to multidimensional frailty of older people in order to identify risk profiles. The growing number of potentially frail older people demands preventive initiatives to maintain qualitative independent living among older people (Stijnen, Jansen, Vrijhoef, \& Duimel-Peeters, 2013). By gaining insight into the group of older people who are at risk of frailty, public policy and healthcare organizations can recognize and promote care and support that is more individually tailored to people's specific care and support needs (De Witte, De Donder et al., 2013; De Witte, Gobbens et al., 2013). However, experts in preventive elderly care have highlighted the difficulties in identifying the target group that would benefit the most from proactive delivery of care and support (Lette, Baan, van den Berg, \& de Bruin, 2015). Knowledge about these risk target groups in this study will aid social and health care professionals to more accurately detect older people at risk of frailty.

A key finding of this study is that the risk profiles differ across the frailty domains, demonstrating that (prevention of) frailty should be perceived from a multidimensional perspective. Table 3 shows the risk profiles according to the four frailty domains and multidimensional frailty (all the domains of frailty assessed together).

Concerning age, negative gradients were found for physical, social and multidimensional frailty. This is partly in line with earlier research from Coelho, Paùl, Gobbens, and Fernandes (2015b), in which a negative association was also found, but only in the physical domain of frailty. The relationship between physical frailty and age has been thoroughly studied (Curcio, Henao, \& Gomez, 2014; Garcia-Garcia et al., 2011) and these have studies confirmed that age has a negative impact on physical frailty. Our results add that physical frailty starts as early as from the age of 65 years, contributing to the findings of studies that have examined frailty only from the age of 75 years (Gobbens \& van Assen, 2014) and 85 years (Nicholson, Meyer, Flatley, Holman, \& Lowton, 2012). The connection between social frailty and age may be clarified by the rationale that when people age, their social network decreases for reasons such as the loss of their partner, family, friends, divorce, and their children leaving the family home (van Groenou, Hoogendijk, \& van Tilburg, 2013).
For the second sociodemographic characteristic, marital status, the observed relationship with the different frailty domains differed between men and women. Never-married men were more likely to be psychologically and environmentally frail compared to never-married women. For both men and women, being divorced or widowed was negatively associated with psychological frailty, which may be linked with the strong negative impact of losing one's partner through divorce or death on one's emotional well-being (Kamiya, Doyle, Henretta, \& Timonen, 2013).

Country of birth, as the third sociodemographic characteristic, appeared to be associated with environmental frailty. Men originating from the European Union (EU) and both men and women originating from outside the EU appeared to be more environmentally frail compared to native Belgian older people. To our knowledge, the relationship between country of birth and environmental frailty is almost non-existent, and needs further research (Brothers, Theou, \& Rockwood, 2014).

Moving house has been negatively associated with physical, psychological, social, and multidimensional frailty. The negative relationship with social frailty might imply that moving makes it challenging for older people in terms of creating new social contacts and integrating into a new neighborhood (Löfqvist et al., 2013). Conversely, women who moved in the last 10 years were less likely to be environmentally frail. In other words, among women, moving appeared to be a protective factor for environmental frailty. In line with our results, other studies have showed that women are more leniently to move to age-adapted housing types (Tang \& Lee, 2011).

Socioeconomic characteristics also play a strong role in frailty. In both men and women, lower levels of education and household income are related to increased levels of frailty. These results are related to the positive effect of education on health and health behaviors (Brunello, Fort, Schneeweis, \& Winter-Ebmer, 2015; Silles, 2009). Likewise, older people who have higher levels of education are less likely to feel lonely (Hawkley et al., 2008; Victor \& Yang, 2012).

Within this study, some limitations should be noted that warrant further consideration and research. First, this research had a small population of people older than 60 years born outside Belgium (1.2\% of these older people were born in Europe and $0.4 \%$ outside Europe). Thus, the study population could be considered as non-representative, since $2.16 \%$ of all Belgian older people (65+ years) in 2004 were born outside Belgium (BAS data: $1.5 \%$ of people older than 65 years) (Lodewijck, 2007). Moreover, this migrant older population is also mainly represented in the youngest older age group, from 60 to

Table 3. Overview of the risk profiles for the frailty domains and multidimensional frailty.

\begin{tabular}{|c|c|c|c|c|}
\hline Physical frailty & Psychological frailty & Social frailty & Environmental frailty & Frailty total \\
\hline \multicolumn{5}{|c|}{ Similar risk characteristics among older men and women } \\
\hline \multirow[t]{3}{*}{ Older } & & & & Older \\
\hline & & Unmarried & & Unmarried \\
\hline & & & Born outside Belgium & \\
\hline Moved in the previous 10 years & Moved in the previous 10 years & $\begin{array}{l}\text { Moved in the previous } \\
10 \text { years }\end{array}$ & & Moved in the previous 10 years \\
\hline Lower education & Lower education & & Lower education & Lower education \\
\hline Lower household income & Lower household income & Lower household income & Lower household income & Lower household income \\
\hline \multicolumn{5}{|c|}{ Different risk characteristics among older men and women } \\
\hline & Men living alone & & Divorced and widowed women & \\
\hline & Widowed or divorced women & & Never-married and divorced men & \\
\hline & & & & $\begin{array}{l}\text { Having moved in the previous } \\
10 \text { years was a protective factor } \\
\text { for women }\end{array}$ \\
\hline
\end{tabular}


69 years. This could explain why country of birth has little significance for frailty in older people. Further studies could provide more evidence on this matter; Brothers et al. (2014) concluded that country of birth was associated with frailty. Second, cognitive frailty was not included in the CFAl, but is an important domain of multidimensional frailty (Qingwei et al., 2015). All the respondents were cognitively healthy. Third, understanding frailty from a multidimensional perspective among older adults requires more than only sociodemographic and socioeconomic characteristics; for example, life events (de Vries et al., 2011) or environmental influences such as the number of leisure activities that people are involved in may be potential variables (Chen, Chen, Lue, Tseng, \& Wu, 2014). In addition, factors that may confound the relationships between social factors and frailty, such as lifestyle behaviors, were not controlled for. Fourth, because of the cross-sectional nature of this research, it is not possible to determine the temporality of the relationships between sociodemographic and socioeconomic characteristics and frailty in older people. Longitudinal or retrospective studies could give more detailed evidence on this matter, and could give more insights into the trajectories leading to frailty. Such information might be valuable for developing preventive actions such as preventive home visits (Elkan et al., 2001).

\section{Conclusion}

The current study indicates that in order to prevent frailty in later life, a multifaceted perspective is required. By examining the four domains of frailty separately as well as from a multidimensional perspective, the present study adds to the literature by showing a complex interplay between older individuals' sociodemographic and socioeconomic characteristics, on the one hand, and frailty and its domains, on the other hand. A key finding is that the risk factors and risk profiles differ by frailty domain and gender. The results of this study may help determine domain-specific frailty profiles for the diverse group of older people.

\section{Acknowledgments}

The research of the D-SCOPE consortium, commissioned by the Agency for Innovation by Science and Technology, is embedded in the Strategic Basic Research (IWT-140027-SBO). The authors especially thank the older volunteers for their commitment and enthusiasm. We acknowledge the provincial and local governments for their support acooperation throughout the research.

\section{Disclosure statement}

The authors declare that they have no conflicts of interest with respect to the research, authorship, and/or publication of this article. All authors are part of the D-SCOPE consortium and declare to have contributed in a substantial manner.

\section{Funding}

This work was supported by the Agency for Innovation by Science and Technology Flanders [grant number IWT-140027-SBO].

\section{ORCID}

Ellen De Roeck iD http://orcid.org/0000-0002-6566-6562

\section{References}

Börsch-Supan, A., Brandt, M., Hunkler, C., Kneip, T., Korbmacher, J., Malter, F., ... Zuber, S. (2013). Data resource profile: The survey of health, ageing and retirement in Europe (SHARE). International Journal of Epidemiology, 42(4), 992-1001.

Bravell, M., Westerlind, B., \& Midlöv, P. (2011). How to assess frailty and the need for care? Report from the Study of Health and Drugs in the Elderly (SHADES) in community dwellings in Sweden. Archives of Gerontology and Geriatrics, 53(1), 40-45.

Brothers, T.D., Theou, O., \& Rockwood, K. (2014). Frailty and migration in middle-aged and older Europeans. Archives of Gerontology and Geriatrics, 58(1), 63-68. doi:10.1016/j.archger.2013.07.008

Brunello, G., Fort, M., Schneeweis, N., \& Winter-Ebmer, R. (2015). The causal effect of education on health: What is the role of health behaviors? Health Economics, 280, 314-336. doi:10.1002/hec.3141

Buckinx, F., Rolland, Y., Reginster, J.-Y., Ricour, C., Petermans, J., \& Bruyère, O. (2015). Burden of frailty in the elderly population: Perspectives for a public health challenge. Archives of Public Health, 73(1), 19. doi:10.1186/s13690-015-0068-x

Chen, L.-J., Chen, C.-Y., Lue, B.-H., Tseng, M.-Y., \& Wu, S.-C. (2014). Prevalence and associated factors of frailty among elderly people in Taiwan. International Journal of Gerontology, 8(3), 114-119. doi:10.1016/j. ijge.2013.12.002

Coelho, T., Paúl, C., Gobbens, R.J.J., \& Fernandes, L. (2015a). Multidimensional frailty and pain in community dwelling elderly. Pain Medicine. doi:10.1111/pme.12746

Coelho, T., Paúl, C., Gobbens, R.J.J., \& Fernandes, L. (2015b). Determinants of frailty: The added value of assessing medication. Frontiers in Aging Neuroscience, 7, 56. doi:10.3389/fnagi.2015.00056

Curcio, C.-L., Henao, G.-M., \& Gomez, F. (2014). Frailty among rural elderly adults. BMC Geriatrics, 14, 2. doi:10.1186/1471-2318-14-2

De Donder, L., De Witte, N., Verté, D., Dury, S., Buffel, T., Smetcoren, A.-S., ... Verté, E. (2014). Developing evidence-based age-friendly policies: A participatory research project. In Research methods cases. London: SAGE. doi:10.4135/978144627305013508507

De Lepeleire, J., Iliffe, S., Mann, E., \& Degryse, J.M. (2009). Frailty: An emerging concept for general practice. British Journal of General Practice, 59(562), 177-182. doi:10.3399/bjgp09X420653

de Vries, N.M., Staal, J.B., van Ravensberg, C.D., Hobbelen, J.S.M., Rikkert, M. G.M.O., \& Nijhuis-van der Sanden, M.W.G. (2011). Outcome instruments to measure frailty: A systematic review. Ageing Research Reviews, 10(1), 104-114. doi:10.1016/j.arr.2010.09.001

De Witte, N., De Donder, L., Dury, S., Buffel, T., Verté, D., \& Schols, J. (2013). A theoretical perspective on the conceptualisation and usefulness of frailty and vulnerability measurements in community dwelling older adults. Aporia: The Nursing Journal, 5(1), 13-31.

De Witte, N., Gobbens, R., De Donder, L., Dury, S., Buffel, T., Schols, J., ... Verte, D. (2013). The comprehensive frailty assessment instrument: Development, validity and reliability. Geriatric Nursing, 34(4), 274-281. doi:10.1016/j.gerinurse.2013.03.002

Drubbel, I., Bleijenberg, N., Kranenburg, G., Eijkemans, R.J.C., Schuurmans, M.J., de Wit, N.J., ... Numans, M.E. (2013). Identifying frailty: Do the Frailty Index and Groningen Frailty Indicator cover different clinical perspectives? A cross-sectional study. BMC Family Practice, 14, UNSP 64. doi:10.1186/1471-2296-14-64

Elkan, R., Kendrick, D., Dewey, M., Hewitt, M., Robinson, J., Blair, M., ... Brummell, K. (2001). Effectiveness of home based support for older people: Systematic review and meta-analysis. British Medical Journal, 323(7315), 719-724. doi:10.1136/bmj.323.7315.719

Etman, A., Burdorf, A., Van der Cammen, T.J.M., Mackenbach, J.P., \& Van Lenthe, F.J. (2012). Socio-demographic determinants of worsening in frailty among community-dwelling older people in 11 European countries. Journal of Epidemiology and Community Health, 66(12), 1116-1121. doi:10.1136/jech-2011-200027

Etman, A., Kamphuis, C.B.M., van der Cammen, T.J.M., Burdorf, A., \& van Lenthe, F.J. (2015). Do lifestyle, health and social participation mediate educational inequalities in frailty worsening? European Journal of Public Health, 25(2), 345-350. doi:10.1093/eurpub/cku093

Ferrucci, L., Guralnik, J.M., Studenski, S., Fried, L.P., Cutler, G.B., \& Walston, J.D. (2004). Designing randomized, controlled trials aimed at preventing or delaying functional decline and disability in frail, older persons: A consensus report. Journal of the American Geriatrics Society, 52(4), 625-634. doi:10.1111/j.1532-5415.2004.52174.x 
Field, A. (2013). Discovering statistics using IBM SPSS statistics. London: SAGE.

Fried, L.P., Ferruci, L., Darer, J., Williamson, J., \& Anderson, G. (2004). Untangling the concepts of disability, frailty, and comorbidity: Implications for improved targeting and care. Journals of Gerontology - Biological Sciences and Medical Sciences, 59(3), 255-263.

Fried, L.P., Tangen, C.M., Walston, J., Newman, A.B., Hirsch, C., Gottdiener, J., ... McBurnie, M.A. (2001). Frailty in older adults: Evidence for a phenotype. The Journals of Gerontology Series A: Biological Sciences and Medical Sciences, 56(3), M146-M156.

Garcia-Garcia, F.J., Gutierrez Avila, G., Alfaro-Acha, A., Amor Andres, M.S., De Los Angeles de la Torre Lanza, M.D.L.A., Escribano Aparicio, M.V., Rodriguez-Manas, L. (2011). The prevalence of frailty syndrome in an older population from Spain. The Toledo study for healthy aging. Journal of Nutrition, Health \& Aging, 15(10), 852-856.

Glynn, L.G., Valderas, J.M., Healy, P., Burke, E., Newell, J., Gillespie, P., ... Murphy, A.W. (2011). The prevalence of multimorbidity in primary care and its effect on health care utilization and cost. Family Practice, 28(5), 516-523.

Gobbens, R.JJ., Luijkx, K.G., Wijnen-Sponselee, M.T., \& Schols, J.M.G.A. (2010). Towards an integral conceptual model of frailty. Journal of Nutrition, Health \& Aging, 14(3), 175-181. doi:10.1007/s12603-010-0045-6

Gobbens, R.J.J., \& van Assen, M.A.L.M. (2014). The prediction of quality of life by physical, psychological and social components of frailty in community-dwelling older people. Quality of Life Research, 23(8), 2289-2300. doi:10.1007/s11136-014-0672-1

Gobbens, R.J.J., van Assen, M.A.L.M., Luijkx, K.G., Wijnen-Sponselee, M.T., \& Schols, J.M.G.A. (2010). Determinants of frailty. Journal of the American Medical Directors Association, 11(5), 356-364. doi:10.1016/j. jamda.2009.11.008

Grenier, A. (2007). Constructions of frailty in the English language, care practice and the lived experience. Ageing \& Society, 27(03), 425-445.

Hawkley, L.C., Hughes, M.E., Waite, L.J., Masi, C.M., Thisted, R.A., \& Cacioppo, J.T. (2008). From social structural factors to perceptions of relationship quality and loneliness: The Chicago health, aging, and social relations study. The Journal of Gerontology, Series B: Psychological Sciences and Social Sciences, 63(6), S375-S384.

Hoogendijk, E.O., Muntinga, M.E., van Leeuwen, K.M., van der Horst, H.E., Deeg, D.J.H., \& Frijters, D.H.M.E.A. (2014). Self-perceived met and unmet care needs of frail older adults in primary care. Archives of Gerontology and Geriatrics, 58(1), 37-42. doi:10.1016/j.archger.2013.09.001

Kamiya, Y., Doyle, M., Henretta, J.C., \& Timonen, V. (2013). Depressive symptoms among older adults: The impact of early and later life circumstances and marital status. Aging \& Mental Health, 17(3), 349-357. doi:10.1080/13607863.2012.747078

Kelaiditi, E., Cesari, M., Canevelli, M., Van Kan, G.A., Ousset, P.-J., GilletteGuyonnet, S., ... Vellas, B. (2013). Cognitive frailty: Rational and definition from an (IANA/IAGG) International Consensus Group. Journal of Nutrition Health \& Aging, 17(9), 726-734. doi:10.1007/s12603-0130367-2

Kowal, P., Chatterji, S., Naidoo, N., Biritwum, R., Fan, W., Lopez Ridaura, R., .. Boerma, J.T. (2012). Data resource profile: The world health organization study on global AGEing and adult health (SAGE). International Journal of Epidemiology, 41(6), 1639-1649. doi:10.1093/ije/dys210

Lette, M., Baan, C.A., van den Berg, M., \& de Bruin, S.R. (2015). Initiatives on early detection and intervention to proactively identify health and social problems in older people: Experiences from the Netherlands. BMC Geriatrics, 15(143), 1-13.

Lodewijckx, E. (2007). Ouderen van vreemde herkomst in het Vlaamse Gewest. Origine, sociaaldemografische kenmerken en samenstelling van hun huishouden [Older people with an immigration background in the Flemish Region. Origine, social demographic characteristics and household composition]. Brussel: Studiedienst van de Vlaamse
Regering. [In Dutch]. Retrieved from http://www4.vlaanderen.be/dar/ svr/publicaties/Publicaties/svr-studies/svr-rapport-2007-2.pdf

Löfqvist, C., Granbom, M., Himmelsbach, l., Iwarsson, S., Oswald, F., \& Haak, M. (2013). Voices on relocation and aging in place in very old age. A complex and ambivalent matter. The Gerontologist, 53(6), 919-927. doi:10.1093/geront/gnt034

Mercer, S.W., Smith, S.M., Wyke, S., O'Dowd, T., \& Watt, G.C.M. (2009). Multimorbidity in primary care: Developing the research agenda. Family Practice, 26(2), 79-80. doi:10.1093/fampra/cmp020

Morley, J.E., Vellas, B., \& van Kan, G.A. (2013). Frailty consensus: A call to action. Journal of the American Medical Directors Association, 14(6), 392-397.

Nicholson, C., Meyer, J., Flatley, M., Holman, C., \& Lowton, K. (2012). Living on the margin: Understanding the experience of living and dying with frailty in old age. Social Science \& Medicine, 75(8), 1426-1432. doi:10.1016/j.socscimed.2012.06.011

Qingwei, R., Zhuowei, Y., Ma, C., Zhijun, B., Jin, L., \& Wei, H. (2015). Cognitive frailty, a novel target for the prevention of elderly dependency. Ageing Research Reviews, 20, 1-10. doi:10.1016/j.arr.2014.12.004

Rockwood, K., Fox, R., Stolee, P., Robertson, D., \& Beattie, B. (1994). Frailty in elderly people - an evolving concept. Canadian Medical Association Journal, 150(4), 489-495.

Scharlach, A. (2011). Creating aging-friendly communities in the United States. Ageing International, 37(1), 25-38. doi:10.1007/s12126-011-9140-1

Silles, M.A. (2009). The causal effect of education on health: Evidence from the United Kingdom. Economics of Education Review, 28(1), $122-128$.

Steverink, N., Slaets, J.P.J., \& Schuurmans, H.M. (2001). Measuring frailty. Development and testing of the Groningen Frailty Indicator (GFI). The Gerontologist, 41, 236-237.

Stijnen, M.M.N., Jansen, M.W.J., Vrijhoef, H.J.M., \& Duimel-Peeters, I.G.P. (2013). Development of a home visitation programme for the early detection of health problems in potentially frail community-dwelling older people by general practices. European Journal of Ageing, 10(1), 49-60. doi:10.1007/s10433-012-0251-7

Strandberg, T.E., \& Pitkälä, K.H. (2007). Frailty in elderly people. Lancet, 369 (9570), 1328-1329.

Studenski, S., Hayes, R.P., \& Leibowitz, R.Q. (2004). Clinical global impression of change in physical frailty: Development of a measure based on clinical judgement. Journal of the American Geriatrics Society, 52(9), $1560-1566$.

Syddall, H., Roberts, H.C., Evandrou, M., Cooper, C., Bergman, H., \& Sayer, A.. (2010). Prevalence and correlates of frailty among communitydwelling older men and women: Findings from the Hertfordshire Cohort Study. Age Ageing, 39(2), 197-203.

Tang, F., \& Lee, Y. (2011). Social support networks and expectations for aging in place and moving. Research on Aging, 33(4), 444-464. doi:10.1177/0164027511400631

United Nations (2013). World population ageing 2013: ST/SEA/SER.A/ 348. Retrieved from https://www.un.org/en/development/desa/ population/publications/pdf/ageing/WorldPopulationAgeingRe port2013.pdf

van Groenou, M.B., Hoogendijk, E.O., \& van Tilburg, T.G. (2013). Continued and new personal relationships in later life: Differential effects of health. Journal of Aging and Health, 25(2), 274-295. doi:10.1177/ 0898264312468033

Victor, C.R., \& Yang, K. (2012). The prevalence of loneliness among adults: A case study of the United Kingdom. Journal of Psychology, 146(1-2), 85-104. doi:10.1080/00223980.2011.613875

Walker, A., \& Maltby, T. (2012). Active ageing: A strategic policy solution to demographic ageing in the European Union. International Journal of Social Welfare, 21, S117-S130. doi:10.1111/j.14682397.2012.00871 


\section{Appendices}

\section{Appendix 1. The Comprehensive Frailty Assessment Instrument (CFAI)}

1. Have the following activities been hampered by your state of health? If so, for how long? (Please tick all appropriate items)

\begin{tabular}{|l|l|l|l|}
\hline & $\begin{array}{c}\text { Not } \\
\text { at all }\end{array}$ & $\begin{array}{c}3 \text { months } \\
\text { or less }\end{array}$ & $\begin{array}{c}\text { More than } \\
3 \text { months }\end{array}$ \\
\hline $\begin{array}{c}\text { Less demanding activities like } \\
\text { carrying shopping bags }\end{array}$ & & & \\
\hline Walking up a hill or some stairs & & & \\
\hline Bending or lifting & & & \\
\hline Going for a walk & & & \\
\hline
\end{tabular}

2. Considering the last few weeks, to which extent do you agree with the following (please tick)
$1=$ not at all
$3=$ more than usual

$2=$ not more than usual $4=$ considerably more than usual

\begin{tabular}{|l|l|l|l|l|}
\hline & 1 & 2 & 3 & 4 \\
\hline I feel unhappy and depressed & & & & \\
\hline I feel like I'm losing my self-confidence & & & & \\
\hline I feel like I cannot cope with problems & & & & \\
\hline I feel like I'm under constant pressure & & & & \\
\hline I feel like I'm not worth anything anymore & & & & \\
\hline
\end{tabular}

3. To which extent do you agree with the following statements? (please tick all appropriate items)

$$
\begin{array}{ll}
1=I \text { completely disagree } & 4=\mid \text { agree } \\
2=I \text { disagree } & 5=I \text { completely agree } \\
3=I \text { neither agree nor disagree } &
\end{array}
$$

\begin{tabular}{|l|l|l|l|l|l|}
\hline & 1 & 2 & 3 & 4 & 5 \\
\hline I experience a general sense of emptiness. & & & & & \\
\hline I miss having people around me. & & & & & \\
\hline I often feel rejected. & & & & & \\
\hline $\begin{array}{c}\text { There are enough people whom I can rely on } \\
\text { when I am in trouble. }\end{array}$ & & & & & \\
\hline I know many people whom I can totally trust. & & & & & \\
\hline $\begin{array}{l}\text { There are enough people with whom I feel a } \\
\text { bond. }\end{array}$ & & & & & \\
\hline My house is in a bad condition/poorly kept. & & & & & \\
\hline My house is not very comfortable. & & & & & \\
\hline It is difficult to heat my house. & & & & & \\
\hline There is insufficient comfort in my house. & & & & & \\
\hline I do not like my neighborhood. & & & & & \\
\hline
\end{tabular}

4. Suppose you are unable to carry out the activities you usually do in terms of housekeeping for a certain length of time; who would you be able to appeal to? (Please tick all appropriate items) (More than one answer may be given)

\begin{tabular}{|l|l|}
\hline Partner & \\
\hline Son & \\
\hline Daughter-in-law & \\
\hline Daughter & \\
\hline Son-in-law & \\
\hline Grandchild & \\
\hline Sister or brother (in-law) & \\
\hline Family & \\
\hline Neighbours & \\
\hline Friends & \\
\hline
\end{tabular}


Appendix 2. Table characteristics baseline and comparison within groups (Kruskall-Wallis and Mann-Whitney $U$-test) $(n=28,049)$

\begin{tabular}{|c|c|c|c|c|c|c|c|c|c|c|}
\hline & \multirow{2}{*}{\multicolumn{2}{|c|}{$\frac{\text { Physical frail }}{\chi^{2}(2) / U}$}} & \multirow{2}{*}{\multicolumn{2}{|c|}{$\frac{\text { Psychological frail }}{\chi^{2}(2) / U}$}} & \multirow{2}{*}{\multicolumn{2}{|c|}{$\frac{\text { Social frail }}{\chi^{2}(2) / U}$}} & \multirow{2}{*}{\multicolumn{2}{|c|}{$\frac{\text { Environmental frail }}{\chi^{2}(2) / U}$}} & \multirow{2}{*}{\multicolumn{2}{|c|}{$\frac{\text { Frailty total }}{\chi^{2}(2) / U}$}} \\
\hline & & & & & & & & & & \\
\hline & Men & Women & Men & Women & Men & Women & Men & Women & Men & Women \\
\hline \multicolumn{11}{|l|}{ Sociodemographic characteristics } \\
\hline Age & $1360.3^{* *}$ & $2582.3^{* *}$ & $103.9^{* *}$ & $144^{* *}$ & $42.8^{* *}$ & $50.3^{* *}$ & $17.3^{*}$ & $68.2^{* *}$ & $725.2^{* *}$ & $1588.9^{* *}$ \\
\hline Marital status & $178.9^{* *}$ & $650.1^{* *}$ & $332^{* *}$ & $499^{* *}$ & $322.6^{* *}$ & $238.3^{* *}$ & $116^{* *}$ & $123.8^{* *}$ & $429.3^{* *}$ & $714.8^{* *}$ \\
\hline Country of birth & 4.2 & 0.09 & $9.9^{*}$ & $7.9^{*}$ & 4.1 & 0.7 & $37.3^{* *}$ & $18.6^{* *}$ & $9.7^{*}$ & 2.2 \\
\hline Moved previous 10 years & $11991990.5^{*}$ & $15455028^{* *}$ & $13108419^{* *}$ & $18209775^{* *}$ & $1254726^{* *}$ & $17914450^{* *}$ & 1436292 & $19009227^{* *}$ & $9670068^{* *}$ & $12038409^{* *}$ \\
\hline \multicolumn{11}{|l|}{ Socioeconomic characteristics } \\
\hline Education & $440.3^{* *}$ & $737.1^{* *}$ & $59.9^{*}$ & $91.8^{* *}$ & 10.8 & $29.2^{* *}$ & 2.3 & $27^{* *}$ & $340^{* *}$ & $601^{* *}$ \\
\hline Income & $357.1^{* *}$ & $613^{* *}$ & $146.1^{* *}$ & $237^{* *}$ & $69^{* *}$ & $70.3^{* *}$ & $73.5^{* *}$ & $95^{* *}$ & $469.8^{* *}$ & $721^{* *}$ \\
\hline
\end{tabular}

Note: $\chi^{2}(2)$, Kruskall-Wallis; U, Mann-Whitney; ${ }^{*} p<.01{ }^{* *} p<.001$. 